\title{
Local Copper Coating of the Connectors of the Divertor Target Elements of Wendelstein 7-X
}

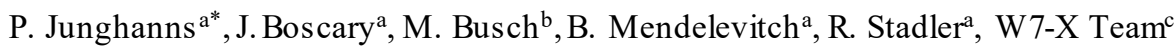 \\ ${ }^{a}$ Max-Planck-Institut für Plasmaphysik, Garching, Germany \\ ${ }^{b}$ Galvano-TGmbH, Windeck/Rosbach, Germany \\ ${ }^{c}$ Max-Planck-Institut für Plasmaphysik, Greifswald, Germany
}

\begin{abstract}
Water connectors of the divertor target elements of Wendelstein 7-X (W7-X) are made of CuCrZr with a Ni (270) transition to stainless steel 316L. A small He leak rate was always detected in the welding area between $316 \mathrm{~L}$ and $\mathrm{Ni}$ of some target elements. To seal these connectors, the coating onto round tubes with very high purity oxygenfree $\mathrm{Cu}$ CW009A was developed. This technology was validated with tests reproducing expected operation conditions in W7-X. Metallography examinations indicated the good adhesion without pores or cracks on connectors. The main characteristics of the coating are: a $\sim 1 \mu \mathrm{m}$ thick Ni interlayer, a $0.3 \mathrm{~mm}$ thick and $20 \mathrm{~mm}$ long $\mathrm{Cu}$ coating. The previous un-tight target elements passed the He leak testing in vacuum oven after coating.
\end{abstract}

Keywords: Stellarator, Wendelstein 7-X, Plasma Facing Component, Divertor, Coating

\section{Introduction}

The highly loaded surface of the actively watercooled divertor of the stellarator Wendelstein 7-X (W7$\mathrm{X})$ is made of 890 target elements. A target element is made of a $\mathrm{CuCrZr}$ copper alloy heat sink armored with carbon fibre reinforced carbon CFC NB31 tiles [1]. The water connectors are produced by electron beam welding thicker tubes of $\mathrm{CuCrZr}$ and 316L (1.4404) stainless steel with a $\mathrm{Ni}$ (270) transition, $5 \mathrm{~mm}$ long [2]. They are then machined at the inside and outside to remove porosities generated by this process. Final dimensions are an internal diameter of $10 \mathrm{~mm}$ and a final thickness of $1 \mathrm{~mm}$. There is only one type of connectors for the target elements. During the production, the manufacturer systematically performed and archived the following non-destructive testing (NDTs) of the individual connectors: visual, dimensions, He-leak testing in atmosphere, X-ray and dye-penetration. Defective connectors cannot be repaired.

In a final stage, the connectors are electron beam welded to the heat sink of the target element for the water inlet and outlet. Depending on the target element type, the two connectors are positioned either horizontally or vertically with respect to the heat sink (Fig. 1).
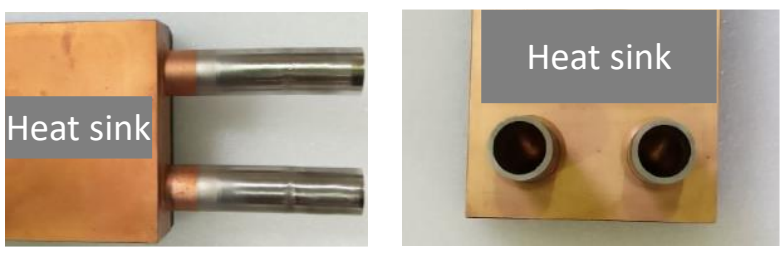

Fig. 1: position of water connectors of target element

The connectors are aged at $475^{\circ} \mathrm{C}$ for 3 hours three times: firstly after the electron beam welding to the heat sink, secondly after the electron beam welding of the top tiles to the heat sink and thirdly after the electron beam welding of the edge tiles to the heat sink. The edge tiles protect the $\mathrm{CuCrZr}$ side facing the pumping gap [3]. The produced target elements are systematically checked by
He sniffing leak testing at atmosphere and examined with ultrasonic.

During the incoming inspection performed by IPP, $5 \%$ of the target elements of the second production phase (33 over 680) did not pass the He leak test in vacuum oven. About $10 \%$ of the series target elements were high heat flux tested in the GLADIS facility [4]. In addition only one element developed a He leak after testing in GLADIS. The acceptance criterion in a vacuum oven is: a leak rate $\leq 5.10^{-7} \mathrm{~Pa} \ell / \mathrm{s}$ at room temperature and 3.2 $\mathrm{MPa}$ internal $\mathrm{He}$ pressure, and a leak rate $\leq 5.10^{-}$ ${ }^{6} \mathrm{Pa \ell} / \mathrm{s}$ at $160^{\circ} \mathrm{C}$ and $2.5 \mathrm{MPa}$ internal He pressure. A defective target element had one or two leaking connectors in the range of $10^{-5}-10^{-6} \mathrm{~Pa} / / \mathrm{s}$. The leak was always found by carefully sniffing at room temperature at the joint between 316 L and Ni (270) (Fig. 2).

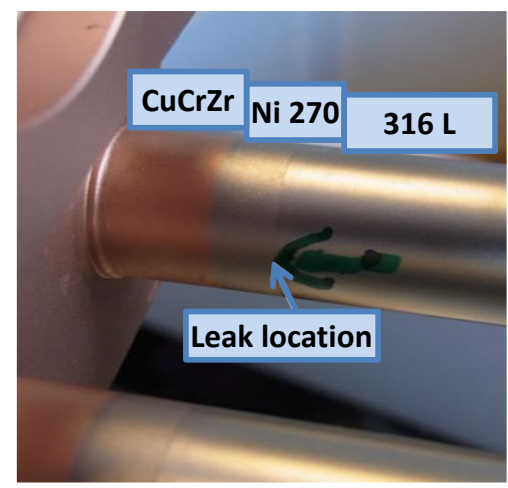

Fig. 2: leak location of water connectors

This percentage of leaking target elements was considered as too high; there was a concern that the $\mathrm{Ni}$ (270) adapter area could be a weak point for the lifetime of the divertor target elements. This paper describes the research activities carried out to develop a solution to strengthen this area for the already produced target elements.

\section{Le akage analys is}


A total of 2000 connectors were produced. Each connector had a series number and was easily traceable. The leaks were randomly distributed: no correlation was found either with the production batches of connectors (welding to heat sinks, ageing in oven) or with the position (left or right). Two charges of $\mathrm{Ni}$ (270) and 3 charges of stainless steel 316L (1.4404) were used. Their chemical analysis did not show any noticeable difference between charges. Detailed analysis of the examination sheets (dye penetration, X-ray) of NDTs and additional examinations such as X-ray, EDX and metallography did not allow understanding the reason for the initiation of these leaks. In this range of He leak rate, the size of the defect is between 0.1 and $1 \mu \mathrm{m}$ diameter. Due to the small size of defects, it seemed difficult to develop a reliable NDT to distinguish better elements than others for the whole production. Mechanical properties of $\mathrm{Ni}$ (270) after ageing were measured and met the specification. Therefore, the explanation of the through path for gas is based on logical assumption which is a combination of small effects: possible impurities in stainless steel raw material and cleaning issues during the electron beam welding. The propagation of this path may be favored in operation by mechanical loads induced by the thermo-mechanical deformation of the divertor target elements under thermal loads.

To solve this issue, the first envisaged solution was the replacement of all water connectors of second production phase of target elements; this process was qualified in the pre-series phase of target elements. Two technologies were evaluated: same or replacing $\mathrm{Ni}$ (270) by Inconel. This approach was not considered further anymore due to the resulting unacceptable delay for the delivery of the divertor. Different attempts such as TIG, laser welding, orbital welding were not successful. The remaining approach was to find a way to improve the present situation by making connectors tight and at the same time reaching better mechanical properties at this location.

\section{Qualification phase}

The electro deposition of copper was successfully used as an efficient repair process for NBI calorimeter plates of ASDEX and also used for the production of the grids of neutral beam sources such as ELISE [5] and the waveguides of the remote-steering launchers of the W7$\mathrm{X}$ ECRH [6]. The application of this technology to the target elements has: (1) to take into account the geometry of the connectors (coating of a tube instead of a flat surface); (2) to get a constant coating thickness around and along the connectors; (3) to be reproducible for hundreds of connectors with a reliable quality assurance; (4) to guarantee the adhesion on 3 different materials (CuCrZr, Ni (270), 316L) in operation; (5) to avoid electrolytic leakage during coating because the target elements are armored with $\mathrm{CFC}$ tiles.

For the coating, the selected $\mathrm{Cu}$ grade is very high purity oxygen-free CW009A, which is a qualified material for $\mathrm{W} 7-\mathrm{X}$ and already used in galvanic process. The selected material for the interlayer is Ni strike, $\sim 1 \mu \mathrm{m}$ thick and $20 \mathrm{~mm}$ long; first attempts with $\sim 1 \mu \mathrm{m}$ thick gold did not show a reliable adhesion. Internal coating was also not successfulwith a very bad adhesion visible on test pieces.

For the qualification phase, full-scale dummy target elements made of $\mathrm{Al}$ were used. Fig. 3 shows the elements used for the qualification of the vertical positioned connectors.

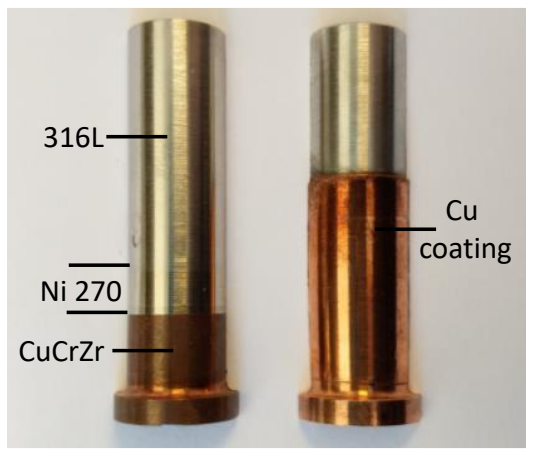

Fig. 3: un-coated and coated connectors

The used test pieces were geometrically non-conform connectors (roundness after machining slightly out of specification). They were aged 3 times to reproduce the material conditions at the end of the fabrication of the target elements. In some test connectors, artificial defects with a diameter of $0.8 \mathrm{~mm}$, were machined at the interface between $\mathrm{Ni}(270)$ and 316L.
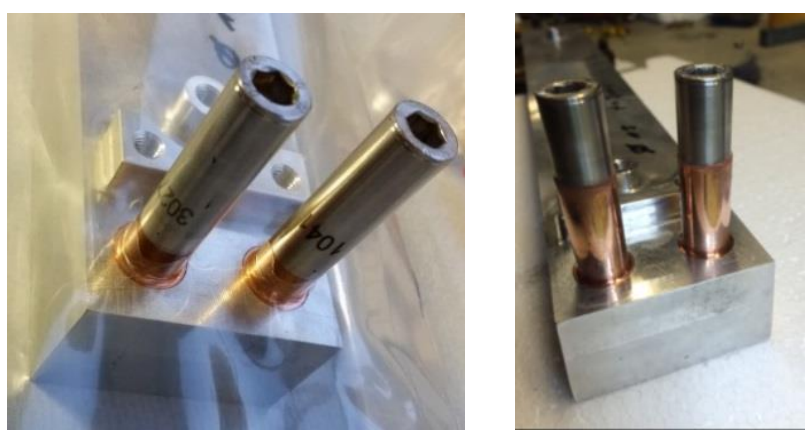

Fig 4: test connectors mounted on dummy Al target element before (left) and after coating (right)

Fig. 4 shows on the left side a dummy target element with test connectors, which has been prepared for coating. The target element is placed into a tight plastic bag as a protection against any possible leakage. The position of the target element is horizontal. Two apertures are made in the bag for the connectors. Before coating, the surface has to be cleaned and degreased. For the deposition process, different geometries of jigs and anodes were designed. The first prototype was a jig and one anode all around the two connectors. This solution did not provide a symmetric and uniform coating thickness around the connectors. The selected design was a jig with two individual apertures for the connectors; in each of them one anode is positioned. Fig. 6 shows the final designed for the series, which is the 
result of many prototypes developed during the qualification phase.

For the first trial, a $0.2 \mathrm{~mm} \mathrm{Cu}$ thickness usually applied for repair was selected. Result of the coating on test pieces is shown on the right side of Fig. 4 still placed on the dummy target element and on the right side of Fig. 3 as individual connector.

The $3 \mathrm{~mm}$ thicker part at the bottom of the connector has been designed to allow the insertion into the dedicated machined holes of the heat sink in a very accurate position before electron beam welding. The $20 \mathrm{~mm}$ coating length is a compromise. It provides a sufficient coating of the connector with a distance between the Ni (270)-316L transition and the end of the coating on the $316 \mathrm{~L}$ side of $5 \mathrm{~mm}$. It provides also sufficient space to allow the further orbital welding to the water-cooling system of the target module. Fig. 5 shows the results of the metallography analysis of a test connector: a very good adhesion of the coating on $\mathrm{Ni}$ (270) and weld seam between Ni (270) and 316L (left) and on $316 \mathrm{~L}$ (right) with no pores and no cracks. The Ni interlayer of the $\mathrm{Cu}$ coating is $1 \mu \mathrm{m}$ thick (difficult to see in Fig. 5).
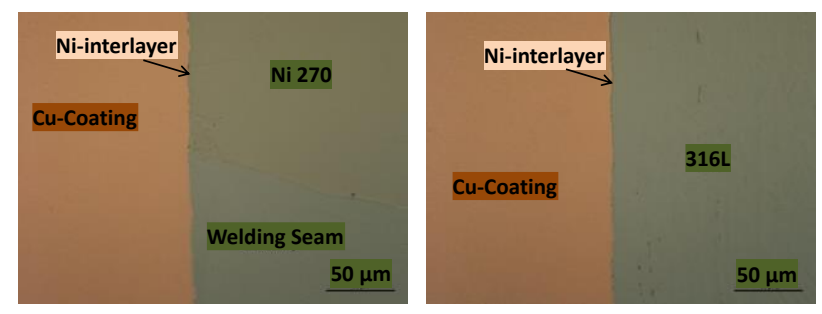

Fig. 5: adhesion of $\mathrm{Cu}$-coating to connector

The next step was the testing of the reliability of the coating for expected operating conditions of the target elements. Finite element calculations showed that the maximal Von Mises stress reached in the Ni (270) adapter induced by the thermal loading of the target element equipped with vertically positioned connectors is $60 \mathrm{MPa}$. A test facility was specially built to perform bending tests on coated connectors. The selected displacement at the $316 \mathrm{~L}$ connector extremity was $0.08 \mathrm{~mm}$, which was the lowest measurable value and corresponds to $82 \mathrm{MPa}$ (higher than calculated). 2000 cycles were performed on test pieces with and without calibrated defects. After testing, visual inspections did not show any detachment of the coating. Afterwards, He leak testing in vacuum oven were carried out: $4 \mathrm{MPa}$ at room temperature followed by $3.2 \mathrm{MPa}$ at $160^{\circ} \mathrm{C}$, cycled 5 times. Measured leak rates of the test pieces before and after testing did not change and met the specification. A final metallography analysis showed a remaining good adhesion of the coating onto the connectors. The result of this phase was the validation of the $\mathrm{Cu}$ coating on the outer surface of the connectors. The final step was to prepare this process for the application to hundreds of series target elements. Additional test pieces were manufactured to ensure a reproducible and uniform coating thickness by improving the geometry of the jigs and the position of the anode inside the jig, by adjusting the coating parameters (current, voltage, duration) and by defining the characteristics of the pumps. The outcome was the design of the work station for the series for target elements with vertically positioned connectors.

\section{Local coating for se ries target elements}

For the series, the selected parameters for the coating are a thickness of $0.3(+0.05 /-0) \mathrm{mm}$ and a length of $20(+0 /-1) \mathrm{mm}$. The coating thickness was increased by $0.1 \mathrm{~mm}$ for better reproducibility conditions. As described in the qualification phase, the first step is the protection of the target element in a tight plastic bag against any possible leakage. Inside the bag, the cathode is connected to one of the stud of the $\mathrm{CuCrZr}$ heat sink. Two apertures are made for the connectors. The qualification phase showed that a reliable coating requires a perfectly cleaned surface. The surface is carefully cleaned with ultra-fine Scotch-Brite ${ }^{\mathrm{TM}}$ hand pads. The circumference of the connector is divided in 3 sectors of $120^{\circ}$ to be brushed successively. The possible dusts generated by brushing are removed with compressed air and the surface is carefully visual inspected. Then the bottom part of each aperture of the connectors in the plastic bag is sealed with an O-ring made of silicone. The jig made of ABS-plastic (Fused Filament Fabrication (FFF) filament) is manufactured with a 3D-printer and has apertures for flowing inlet and outlet (Fig. 6). The jig is clamped with screws around the connectors of the target element. An insoluble MOX-Ti anode (Fig. 6) is placed around each of the connector. This anode is accurately positioned to guarantee a uniform coating thanks to slots manufactured in the jig. A plastic cup is mounted on the top part of each connector to seal them and at the same time to define the length to be coated (Fig. 6). At this stage, the tightness of the protection system is tested with flowing water for $10 \mathrm{~min}$.

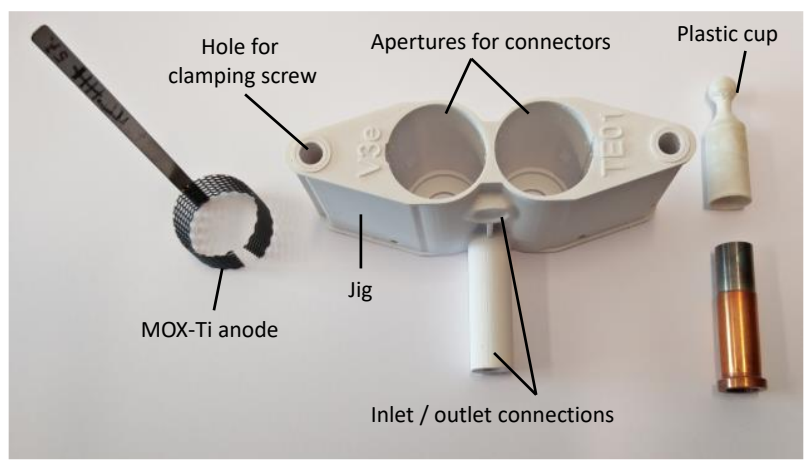

Fig. 6: Component of the coating process:jig, MOX-Ti anode, plastic cup of the connectors

The process started with the electrolytic degreasing of the connectors for $5 \mathrm{~min}$. with a current of $830 \mathrm{~mA}$ followed by flushing water for $2 \mathrm{~min}$.. After draining, the $\mathrm{Ni}$-anode is installed and the deposition of the $\sim 1 \mu \mathrm{m}$ interlayer with Ni-strike lasts 5 min with a current of $360 \mathrm{~mA}$. The Ni-anode is removed and immediately 
after, to avoid oxidation of the $\mathrm{Ni}$ interlayer, the electrolytic $\mathrm{Cu}$ circulates in the jig for a duration of 7 hours with a current of $260 \mathrm{~mA}$. At the end of the process, the connectors are systematically visually controlled to detect possible defect at the coated surface or at the boundaries such as pores or cracks. Pictures of the coated connectors are archived. The coated area is measured at different length: bottom, centre and top. For each position the thickness is measured at the angles of $45^{\circ}$ and $135^{\circ}$. The thickness is the difference between coated and non-coated diameters. The measured values are indicated in the report sheet. Fig. 7 shows the results of the coating process of a series target element with vertically positioned connectors.

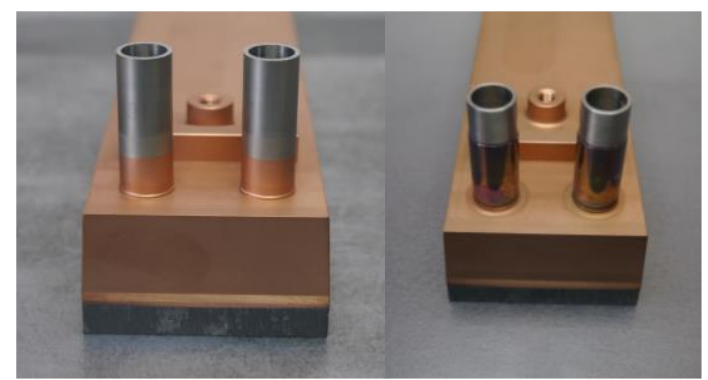

Fig. 7: connectors of series target element before and after coating

In total the coating process of one target element needs about $8 \mathrm{hrs}$. To keep the time schedule for the delivery of the divertor, 3 stations working in parallel have been installed. Each work station has been validated before starting the coating of the series target element; test pieces were coated and analysed with metallography. The results showed the same good quality of the coating and the 3 work stations were released. The reproducibility and the stability of the coating process is a major issue. To guarantee them, frequent replacements of anodes and production of test pieces for metallography analyses have been organized throughout the production. For each work station, the Nianode used for the interlayer is renewed after the production of 5 target elements and the MOX-Ti anode after the production of 10 target elements. After the production of 30 target elements, a test probe is produced for metallography analys is.

The $\mathrm{Cu}$ coating was firstly applied onto the un-tight target elements. After coating the He leak rate of these elements were tested in vacuum oven: $4 \mathrm{MPa}$ at room temperature followed by $3.2 \mathrm{MPa}$ at $160^{\circ} \mathrm{C}$ cycled 3 to 5 times. The coated met the specification and demonstrated the efficiency of the coating. For the tight target elements, no additional leak tests in vacuum oven have been planned.

\section{Conclusion}

The water connectors of the divertor target elements are made of $\mathrm{CuCrZr}$ with a $\mathrm{Ni}$ (270) transition to stainless steel $316 \mathrm{~L}$. $5 \%$ of the phase 2 production of the target elements did not pass the He leak testing in vacuum oven. He sniffing leak testing systematically located the leak at the transition between $\mathrm{Ni}(270)$ and 316L. To solve this issue, the electro deposition of very high purity oxygen-free $\mathrm{Cu}$ CW009A on round tubes was developed. During the qualification phase, metallography analyses showed that a good adhesion on the 3 different materials of the connectors can be achieved. Cycling bending tests and He leak testing in a vacuum oven demonstrated that this technology can withstand the expected operating conditions of the divertor. The coating process started with the target elements, which have vertically positioned connectors. The main characteristics of the coating are: $\mathrm{a} \sim 1 \mu \mathrm{m}$ thick and $20 \mathrm{~mm}$ long $\mathrm{Ni}$ interlayer, a $0.3 \mathrm{~mm}$ thick and $20 \mathrm{~mm}$ long $\mathrm{Cu}$ coating. The previous un-tight target elements passed the He leak testing in vacuum oven after coating. The coating of the first $\sim 300$ target elements of the phase 2 production which have vertical connectors has been completed. The remaining $\sim 300$ target elements have horizontally positioned connectors. For the coating process, these elements have to be vertically positioned instead of horizontally. A new set of support needs to be developed and the working station has to be adapted to this new position. The series production will start once each working station will be released based on the results of the metallography analysis of test connectors.

Next step is the individual 3D-machining of the target element before assembly as target modules. The completion of the target modules is planned by mid-2018 to allow operation in 2020 .

\section{References}

[1] J. Boscary, T. Friedrich, H. Greuner, W. Schulmeyer, R. Stadler, et al., Summary of the Production of the Divertor Target Elements of Wendelstein 7-X, this conference.

[2] B. Tabernig, F. Rainer, K. H. Scheiber, B. Schedler, Improved $\mathrm{CuCrZr} / 316 \mathrm{~L}$ transition for plasma facing components, Fus. Eng. Des. 82 (2007) 1793-1798 (doi:10.1016/j.fusengdes.2007.04.015).

[3] J. Boscary, A. Peacock, T. Friedrich, H. Greuner, B. Böswirth, et al., Design improvement of the target elements of Wendelstein 7-X divertor, Fus. Eng. Des. 87 (2012) 1453-1456 (doi:10.1016/j.fusengdes.2012.03.034.

[4] H. Greuner, U. v. Toussaint, B. Böswirth, J. Boscary, A. Peacock, Results and consequences of high heat flux testing as quality assessment of the Wendelstein 7-X divertor, Fus. Eng. Des. 88 (2013) $581-584$ (doi:10.1016/j.fusengdes.2013.05.044).

[5] B. Heinemann, H. Falter, U. Fantz, P. Franzen, M. Fröschle, et al., Design of the "half-size" ITER Neutral Beam Source for the Test Facility ELISE, Fus. Eng. Des. $84(2-6) \quad$ (2009) 915-922 (doi:10.1016/j.fusengdes.2008.11.076).

[6] W. Kasparek, C. Lechte, B. Plaum, A Zeitler, V. Erckmann, et al., Remote-steering Launchers for the ECRH system on the Stellarator W7-X, EPJ Web of Conferences 87 (2015) 04005. 